\title{
MộT SỐ CƠ SỞ KHOA HỌC ĐỂ NHẬN ĐỊNH NGUỒN NƯỚC MÙA CẠN VÀO VIÊTT NAM TRÊN LƯU VỰC MÊ CÔNG
}

\author{
Trần Đức Thiện ${ }^{1}$, Lưu Thị Hồng Linh ${ }^{1}$
}

Tóm tắt: Thông báo sớm nguồn nước về mùa cạn hàng năm vào đồng bằng sông Cửu Long có ý nghĩa rất quan trọng trong việc chủ động phòng tránh hạn hán thiếu nước, xâm nhập mặn. Đặc điểm thủy văn của lưu vục sông Mê Công và Biển Hồ là diện tích lớn dòng chảy mùa cạn được đóng góp chính bới sông Mê Công và sông Tonle Sap. Do vậy nhận định sớm khả năng nguồn nước vào Việt Nam về mùa cạn là khả thi. Nhận định sớm nguồn nuớc mùa cạn căn cứ vào thông tin nguồn nước trong mùa lũ và lượng trũ lớn nhất của hồ Tonle Sap. Mặt khác, nhận định quy mô năm nước lớn hay bé lại căn cứ vào đường trũ nước lũ tiềm năng của lưu vục. Quan hệ lưu lương giữa các tháng liền kề khá chặt chẽ (hệ số tuơng quan lớn hơn 0,8) là co sở để dụ báo dòng chảy tháng tiếp theo. Một quy trình nhận định sớm dòng chảy vào Việt Nam trong mùa cạn cũng được đề xuất trong khuôn khổ bài báo này.

Từ khóa: Nhận định nguồn nước mùa cạn, Lư vực sông Mê Công.

Ban Biên tập nhận bài: 08/04/2019 Ngày phản biện xong: 20/6/2019 Ngày đăng bài: 25/06/2019

\section{1. Đặt vấn đề}

Hiện nay, dự báo thủy văn và nguồn nước cho Đồng bằng Sông Cửu Long (ĐBSCL) được một số cơ quan thực hiện như Trung tâm dự báo KTTV Trung ương [1], Viện Quy hoạch thủy lợi Miền Nam [2], Viện Khoa học Thủy lợi Miền Nam. Thời gian nhận định nguồn nước vào Việt Nam trong mùa cạn của các cơ quan chỉ là 1 tuần và 15 ngày, với các thông tin là lưu lượng hoặc mực nước tại Tân Châu, Châu Đốc.

Vấn đề đặt ra là để chủ động trong việc khai thác sử dụng nước, phòng tránh hạn hán thiếu nước, xâm nhập mặn đối với ĐBSCL có thể thực hiện được nếu:

- Nhận định sớm lượng nước vào Việt Nam trong mùa cạn.

- Thông báo, dự báo lượng nước vào Việt Nam theo thời gian dài hơn: 15 ngày, tháng, mùa ... trong mùa cạn.

- Nhận định sớm mức độ hạn hạn, xâm nhập mặn trong mùa cạn.

Mục đích của nghiên cứu này: Nghiên cứu

${ }^{1}$ Viện Khoa học tài nguyên nước

Email: thientd810@wru.vn đặc điểm dòng chảy vào ĐBSCL để tìm được cơ sở thực tiễn của việc nhận định sớm lượng nước vào Việt Nam trong mùa cạn.

\section{Phương pháp nghiên cứu và thu thập tài} liệu

a) Phạm vi nghiên cưu

Dòng chính sông Mê Công tính từ trạm thủy văn Kratie tại Cam Pu Chia đến vị trí 2 trạm thủy văn Tân Châu và Châu Đốc và sông Tonle Sap thuộc Cam Pu Chia (hình 1).

b) Dũ liệu

Trong nghiên cứu này, các dữ liệu thu thập có nguồn gốc từ cơ sở dữ liệu của hệ thống hỗ trợ ra quyết định Decision Support Framework (DSF) [6] và các bản tin dự báo [7] của Ủy hội sông Mê Công quốc tế, với số liệu thủy văn tại các trạm Kratie, Kongpong Luong, Prek Dam, Tân Châu và Châu Đốc cập nhật đến 2018.

c) Cơ sở khoa họ nhận định sớm dòng chảy mùa cạn vào Việt Nam trên lưu vưc Mê Công

Dòng chảy mùa cạn vào Việt Nam chủ yếu do lượng nước trên dòng chính sông Mê Công và từ hồ Tonle Sap cung cấp. Nhận định sớm lượng dòng chảy này trong mùa cạn có thể thực 
hiện được vì:

- Lưu vực Mê Kông có diện tích rất lớn do đó có tính điều tiết cao. Đường quá trình nước rút trong mùa cạn phụ thuộc chặt chẽ vào nền nước trong mùa lũ. Tức là những năm lũ lớn thì dòng chảy cạn dồi dào. Dòng chảy mùa lũ quyết định dòng chảy cạn.

- Lượng mưa mùa cạn không quyết định nhiều đến dòng chảy mùa cạn.

- Dòng chảy mùa lũ trên dòng chính quyết định lượng trữ hồ Tongle Sap.

- Hồ Tonle Sap vào mùa cạn chiếm 30-40\% dòng chảy vào Việt Nam. Dòng chính đóng góp $60-70 \%$.

- Hệ thống trạm đo trên dòng chính đầy đủ số liệu.

- Hiện nay, các hồ chứa trên dòng chính hạ lưu Mê Công là đập dâng toàn tuyến điều tiết ngày đêm, ít ảnh hưởng đến đường nước rút. Trong mùa cạn, thông tin điều tiết nước của các hồ phía Trung Quốc, có thể biết được thông qua số liệu tại trạm Chieng Sean nằm ở biên giới Trung Quốc, Lào và trên 20 ngày sau mới ảnh hưởng đến Việt Nam. Tỉ lệ đóng góp dòng chảy trong mùa cạn phần lưu vực thuộc Trung Quốc so với toàn lưu vực khoảng $24 \%$, còn lại chủ yếu là phần hạ lưu.

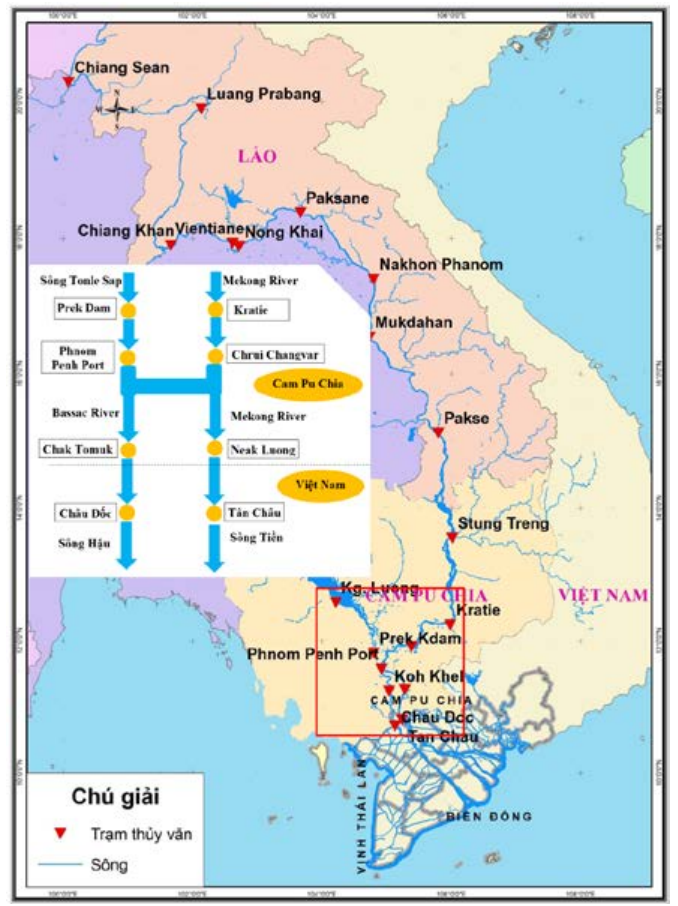

Hình 1. Bản đồ hạ luu sông Mê Công

\section{d) Phuoong pháp nghiên cứu}

Trong nghiên cứu này, chúng tôi sử dụng phương pháp thống kê, phân tích một cách hệ thống từ các số liệu về thủy văn của các trạm Kratie, Kongpong Luong, Prek Dam, Tân Châu và Châu Đốc. Trên cơ sở phân tích số liệu thủy văn kết hợp với đặc điểm địa lý tự nhiên, quy luật hình thành dòng chảy của lưu vực sông Mê Công trước khi chảy vào Việt Nam, nghiên đưa ra được các cơ sở khoa học và thực tiễn cụ thể nhằm nhận định nguồn nước mùa cạn vào Việt Nam trên lưu vực sông Mê Công.

\section{Phân tích kết quả và thảo luận.}

\subsection{Một số đặc điểm lũ tại Krattie quyết} định đến nhận dạng nguồn nước mùa cạn.

Lưu vực sông Mê Công như một hồ chứa khổng lồ, trữ nước vào mùa mưa, điều tiết cho mùa cạn. Lưu vực càng lớn tính điều tiết càng cao và lượng trữ nước tiềm năng cho mùa cạn càng dồi dào. Do đó, lượng nước về mùa lũ có vai trò quyết định đến lượng nước mùa cạn. Nghiên cứu sử dụng số liệu mực nước tại Kratie đo từ 1960 đến 2018, quan hệ Q-H mà Ủy hội Mê Công đang dùng trong dự báo để xác định được lưu lượng nước tại trạm Kratie. Kết quả phân tích cho thấy quan hệ lưu lượng trung bình $\left(\mathrm{Q}_{\mathrm{tb}}\right)$ mùa cạn với $\mathrm{Q}_{\mathrm{tb}}$ mùa lũ và lưu lượng đỉnh lũ của các năm nước ít khá chặt chẽ (hình 2). Điều này cho phép khi kết thúc mùa lũ hoặc kết thúc đỉnh lũ lớn nhất năm ta có thể nhận định được khả năng nguồn nước mùa cạn. Các năm hạn điển hình cho thấy, nếu $\mathrm{Q}_{\max }$ năm nhỏ hơn $35.000 \mathrm{~m}^{3} / \mathrm{s}$, hoặc $\mathrm{Q}_{\mathrm{tb}}$ mùa lũ nhỏ hơn 15.000 $\mathrm{m}^{3} / \mathrm{s}$ thì hạn hán chắc chắn xảy ra.

Cũng bởi đặc điểm diện tích lưu vực lớn, lũ tại Kratie có tính phân kỳ lũ rõ rệt. Các trận lũ lớn hơn mức cảnh báo (Alarm level) tại Kratie ( $\mathrm{Z}=22 \mathrm{~m}$ [7]) tập trung trong khoảng khoảng 20/7 đến 30/9, có thể gọi là thời kỳ lũ chính vụ. Như vậy, hàng năm cứ qua 30/9 là khả năng xảy ra lũ lớn trên mức cảnh báo đã hết. Lũ có $\mathrm{Q}_{\max }>35000$ $\mathrm{m}^{3} / \mathrm{s}$ hầu hết rơi trong thời gian từ $25 / 6$ đến $15 / 10$ và qua $15 / 10$ thì coi như kết thúc lũ (hình 3 ). Nếu lũ lớn nhất năm xuất hiện ngoài khoảng thời gian này thì sẽ chỉ là lũ nhỏ và năm đó sẽ là năm hạn. 


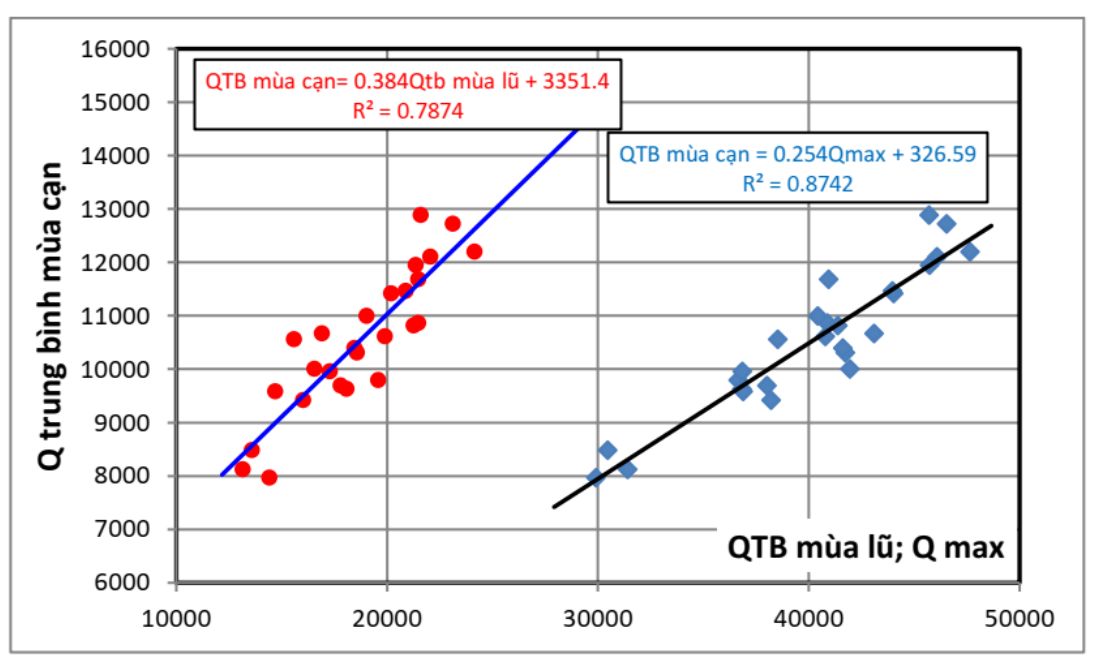

Hình 2. Quan hệ Qtb mùa cạn với $Q_{t b}$ mùa lũ, $Q_{\max }$ của các năm ít nước trạm Kratie

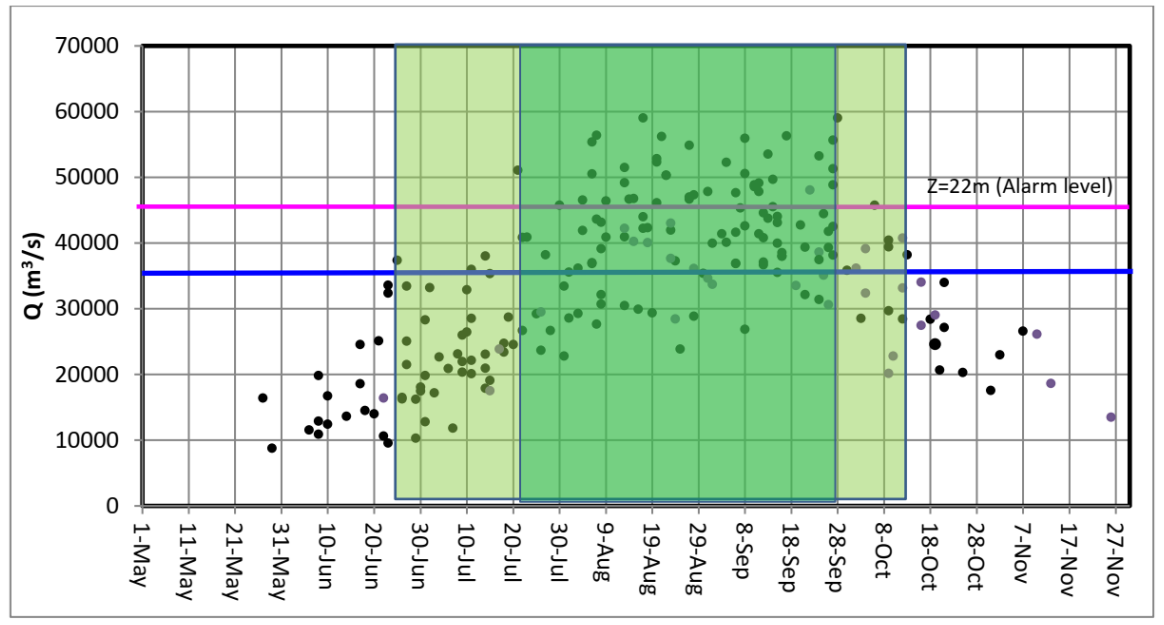

Hìn 3. Phân kỳ lũ tại Kratie

Nhưng việc hình thành lũ lớn trên lưu vực sông Mê Công lại phụ thuộc nhiều vào đường nước nền lũ hay còn gọi là đường trữ nước lũ tiềm năng của lưu vực. Nối chân lũ của các năm lũ nhỏ và lũ lớn ta được đường trữ nước lũ tiềm năng nền và lớn (hình 4). Các đường này và đường $\mathrm{Q}_{\mathrm{tb}}$ mùa lũ chia thành các khu vực như sau:

- Vùng lũ rất nhỏ: Khi đường quá trình lưu lượng trong mùa lũ phát triển dưới đường nước lũ tiềm năng nền.

- Vùng lũ nhỏ: Khi đường quá trình lưu lượng trong mùa lũ phát triển trên đường nước lũ tiềm năng nền và dưới đường lưu lượng lũ trung bình. Điển hình là các năm 1988, 1998, 2010, 2015.
- Vùng lũ lớn: Khi đường quá trình lưu lượng trong mùa lũ phát triển trên đường đường lưu lượng lũ trung bình và dưới đường tiềm năng lũ lớn. Điển hình là các năm 1978, 2001, 2011.

- Vùng lũ lịch sử: Khi đường quá trình lưu lượng trong mùa lũ phát triển trên đường đường tiềm năng lũ lớn. Điển hình là năm 2000.

Theo dõi sự phát triển của đường quá trình dòng chảy trong mùa lũ đến khoảng 20/7 là thời điểm bắt đầu vào thời kỳ lũ chính vụ. Nếu đường quá trình lưu lượng rơi vào vùng nào thì ta có thể nhận định sớm được khả năng lũ của năm đó với mức tin cậy trên $70 \%$ và từ đó nhận định được nguồn nước mùa cạn. 


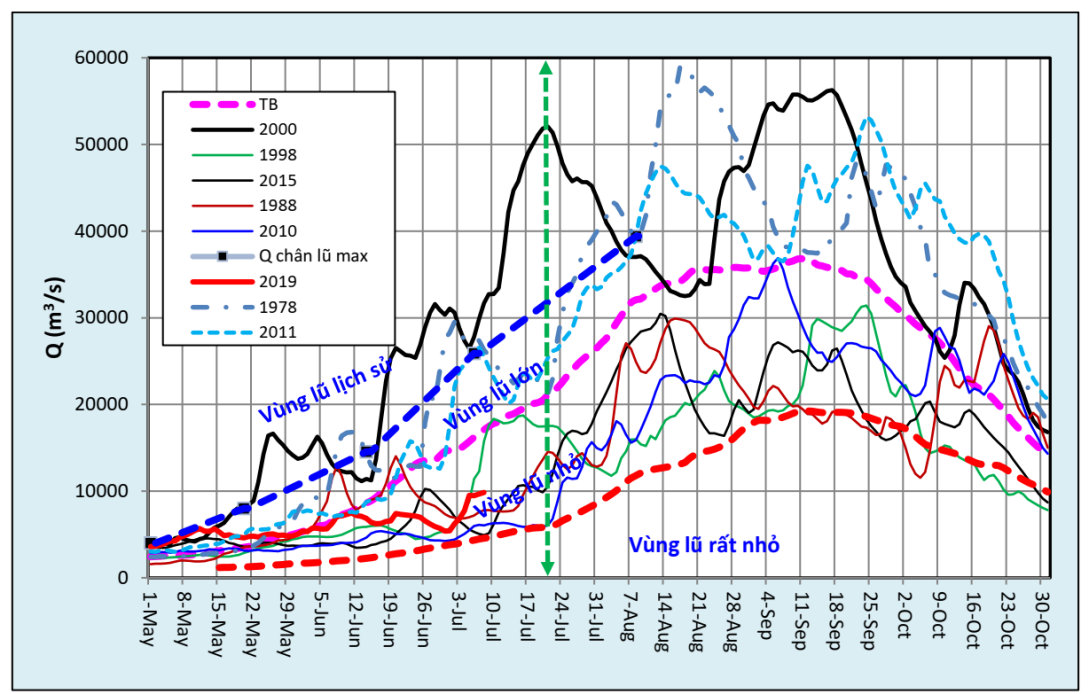

Hình 4. Đuờng trũ nước lũ tiềm năng lưu vục trạm Kratie

3.2. Quan hệ $Q_{\max }$ Krattie với lựng trũ lớn nhất hồ Tonle Sap

Về mùa cạn, hồ Tonle Sap giữ một vai trò quan trọng trong việc cấp nước cho đồng bằng sông Cửu Long. Thông thường hàng năm vào giữa tháng 10 , hồ Tonle Sap bắt đầu đổ về ĐBSCL và kết thúc vào tháng 4 năm sau. Lượng trữ lớn nhất của hồ Tong Le Sáp phụ thuộc khá chặt chẽ với lượng nước trên dòng chính sông

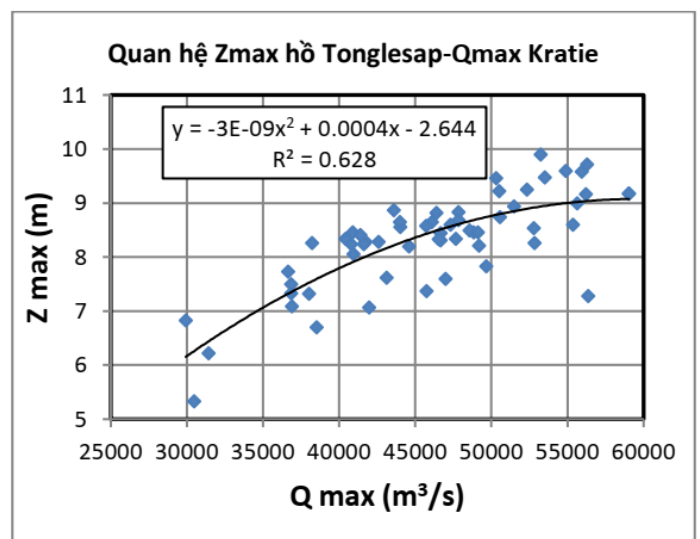

Hình 5. Quan hệ $Z_{\max }$ hồ Tong Lê Sap với $Q_{\max }$ và lưu lượng mùa lũ tại Kratie

3.3. Quan hệ lưu lự̛ng giữa các tháng trong mùa cạn của dòng chảy vào Việt Nam

Để nhận định được dòng chảy trong mùa cạn và dòng chảy các tháng trong mùa cạn, nghiên cứu đã căn cứ vào quan hệ lưu lượng tháng sau với lưu lượng tháng trước đó.

Lượng nước vào Việt Nam về mùa cạn có thể xem như là lượng nước trên dòng chính (lấy tại Kratie) cộng với lưu lượng tại Prek Dam (cửa ra
Mê Công. Thông qua quan hệ mực nước lớn nhất tại trạm Kongpong Luong (đại diện cho mực nước hồ) với $\mathrm{Q}_{\max }$ và $\mathrm{Q}_{\mathrm{tb}}$ mùa lũ mà ta có thể biết được lượng trữ lớn nhất của hồ Tonle Sap (hình 5). Trong nhận định lượng trữ hồ Tông Lê Sáp thông thường dựa vào quan hệ $Z_{\max }$ Tông Lê $\mathrm{Sáp}=\mathrm{F}\left(\mathrm{Q}_{\max }\right.$ Kratie$)$ vì không cần chờ kết thúc mùa lũ để có thông tin $\mathrm{Q}_{\mathrm{tb}}$ mùa lũ mà $\mathrm{Q}_{\max }$ có thể xuất hiện trước đó cả tháng.

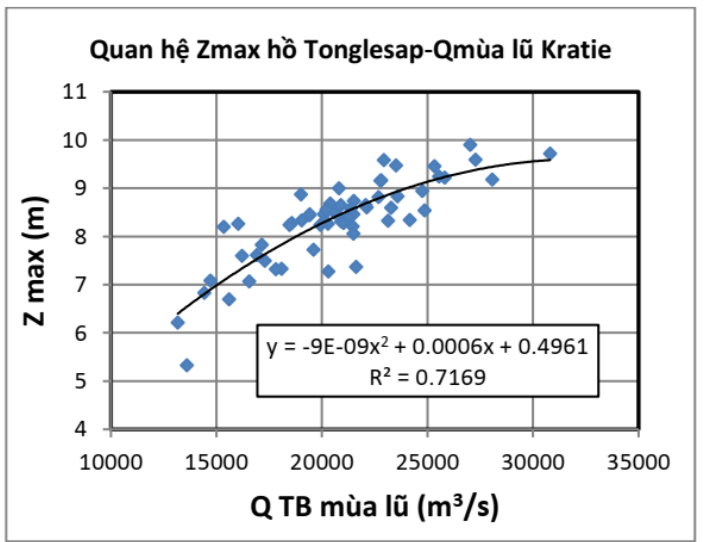

của hồ Tonle Sap). Lưu lượng vào mùa cạn tại Prek Dam được xác định bằng mô hình toán ISIS của Ủy hội sông Mê Công quốc tế và quan hệ Q H tại trạm.

Quan hệ lượng nước vào Việt Nam giữa các tháng vào đầu mùa cạn khá chặt chẽ. Về cuối mùa cạn, khi lượng nước trong hồ Tonle Sap đã gần cạn, thì quan hệ này khá phân tán (hình 6). Lúc này, dòng chính sông Mê Công đóng vai trò 


\section{BÀI BÁO KHOA HỌC}

chủ đạo, đóng góp đến $75-85 \%$ tổng dòng chảy vào Việt Nam. Tại Kratie, quan hệ giữa lưu lượng tháng III với II và IV với III lại rất chặt chẽ (hình 7). Do đó những tháng đầu mùa cạn, dự báo dòng chảy vào Việt Nam theo các tháng dựa vào quan hệ ở hình 6 ; về cuối mùa cạn dựa vào quan hệ ở hình 7 và có tham khảo thêm mực nước hiện trạng của hồ Tonle Sap để đánh giá lượng trữ nước còn lại của hồ.
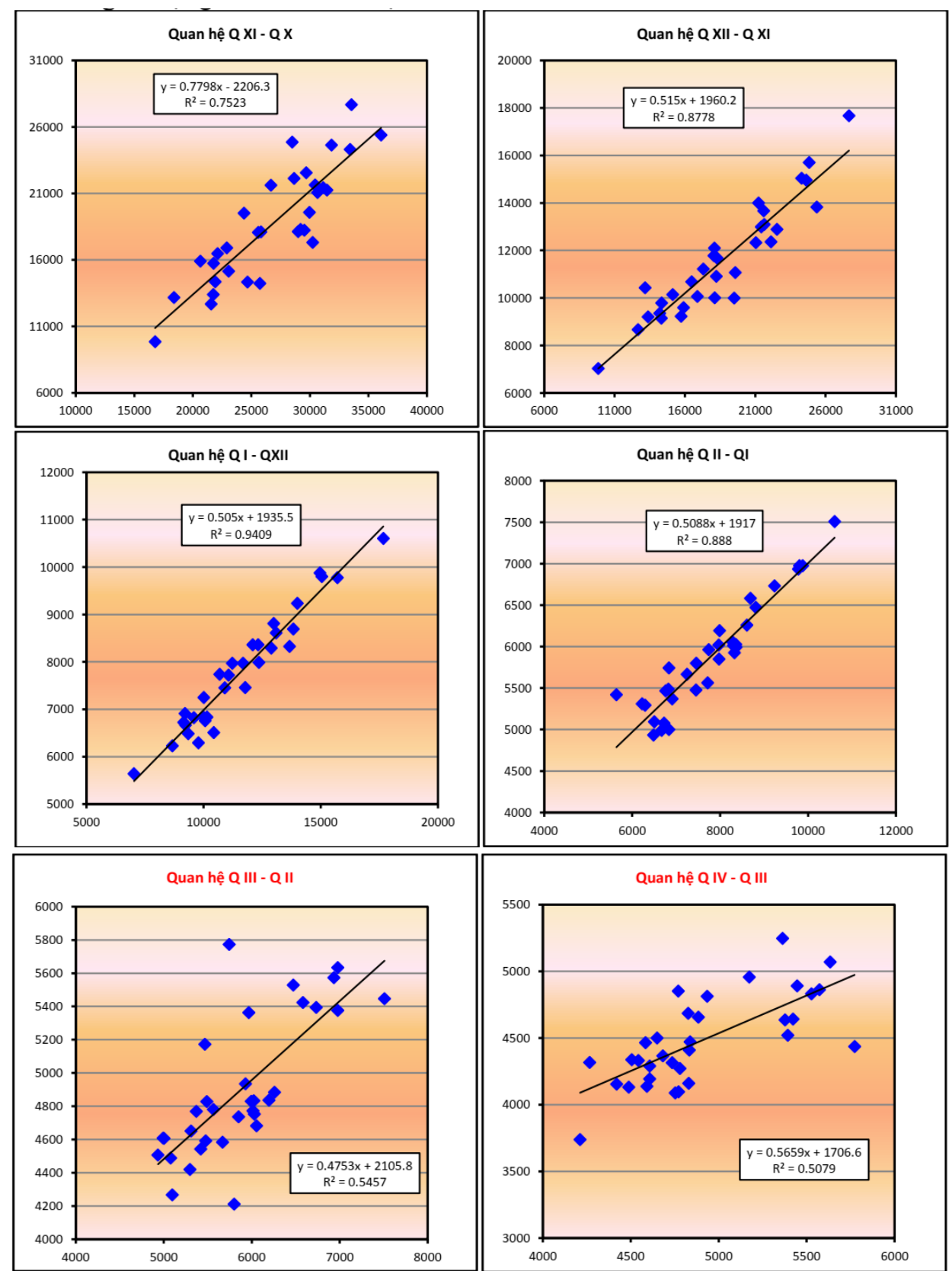

Hình 6. Quan hệ lượng nước vào Việt Nam giữa các tháng trong đầu mùa cạn 

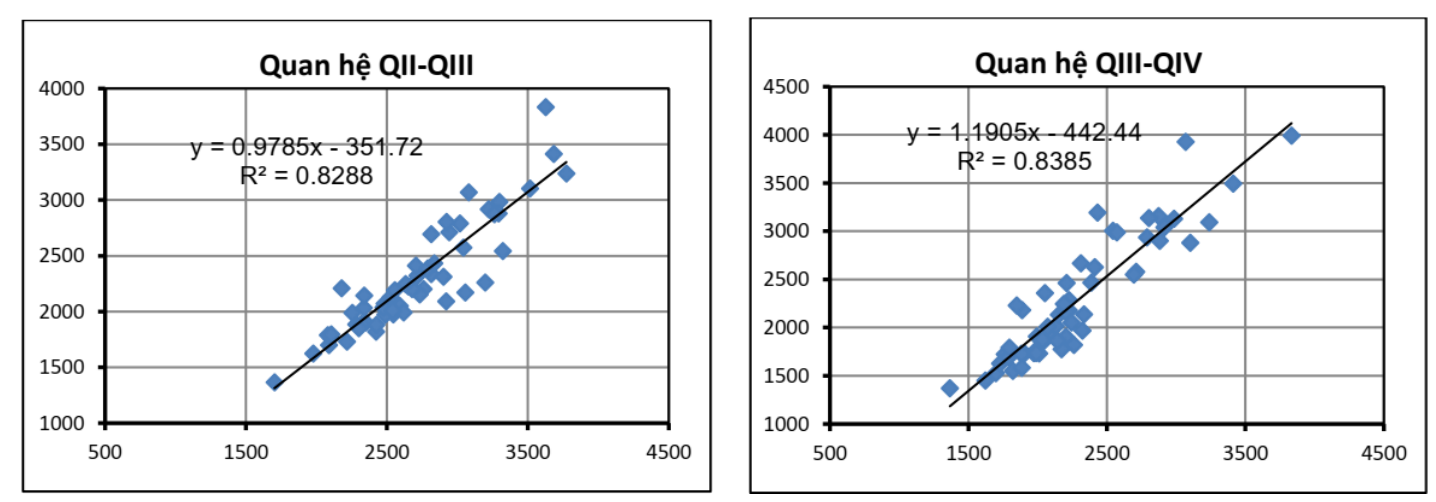

Hình 7. Quan hệ lương giữa các tháng trong mùa cạn tại Kartie

\section{4. Đề xuất quy trình nhận định sớm dòng} chảy vào Việt Nam trong mùa cạn

\section{a. Nhận định $x a$}

Nhận định dòng chảy mùa cạn sông Mê Công vào Việt Nam căn cứ vào thông báo, dự báo khí hậu, tình hình ENSO để nhận định khả năng năm nước ít hay nhiều.

Theo dõi nền nước lũ tiềm năng nhận định khả năng lũ lớn hay bé, hình 4.

Khi xuất hiện đỉnh lũ năm hoặc kết thúc mùa lũ, đánh giá được $\mathrm{Q}_{\mathrm{tb}}$ mùa cạn trên dòng chính thông qua qua hệ trong hình 2. Dự tính khả năng trữ nước lớn nhất của hồ Tonle Sap nhờ quan hệ hình 5.

Nhận định khả năng nguồn nước trong mùa cạn chảy vào Việt Nam dựa vào thông tin $\mathrm{Q}_{\text {to }}$ mùa cạn trên dòng chính và khả năng trữ nước lớn nhất của hồ Tonle Sap.

\section{b. Nhận định và dư báo tháng.}

Từ tháng XI đến tháng II, qua tổng lưu lượng tại Kratie và Prek Dam tháng trước, thông qua quan hệ trên hình 6 để dự báo dòng chảy vào Việt Nam tháng tiếp theo.

Từ tháng III và IV, căn cứ vào lưu lượng trên dòng chính là chủ yếu thông qua qua hệ hình 7 và lượng trữ nước hiện trạng của hồ Tonle Sap để dự báo dòng chảy vào Việt Nam tháng tiếp theo.

c. Dự báo 15 ngày.

Dùng quan hệ Q15 ngày trước với Q15 ngày tiếp theo để nhận định.

Dùng mô hình toán để dự báo dòng chảy đến
Tân Châu Châu Đốc với biên trên là Q tại Kratie và $\mathrm{Q}$ tại PrekDam, kết hợp kết quả dự báo 15 ngày của Ủy hội sông Mê Công.

Có thể tóm lược quy trình nhận định sớm dòng chảy vào Việt Nam trong mùa cạn như sơ đồ dưới đây (hình 8).

\section{Kết luận}

Với đặc điểm thủy văn của lưu vực sông Mê Công và hồ Tonle Sap, cho phép chúng ta nhận định sớm khả năng nguồn nước vào Việt Nam về mùa cạn. Những năm ít nước điển hình nhận định sớm về quy mô dòng chảy mùa cạn có độ tin cậy cao hơn. Quy trình nhận định sớm dòng chảy mùa cạn dễ dàng tin học hóa, không đòi hỏi kỹ thuật phức tạp.

Để công tác thông báo nguồn nước về mùa cạn hàng năm như một nhiệm vụ thường xuyên, cần phải thực hiện thêm một số nội dung sau:

- Thu thập cập nhật liên tục thông tin dự báo, thực đo từ $\mathrm{MRC}$ và TT DB KTTV

- Phân tích số liệu quá khứ, đánh giá tác động hồ chứa,

- Thu thập thông tin và Phân tích hoạt động ENSO đến khô hạn, xâm nhập mặn ĐBSCL,

- Cập nhật mô hình thủy lực hạ lưu và thượng lưu có xét điều tiết hồ chứa,

- Thu thập, cập nhật số liệu mặn các trạm vùng ven biển.

- Thu thập thông tin độ ẩm lưu vực từ ảnh viễn thám,

- Xây dựng thông báo TNN, đưa lên trang WEB. 


\section{BÀI BÁO KHOA HỌC}

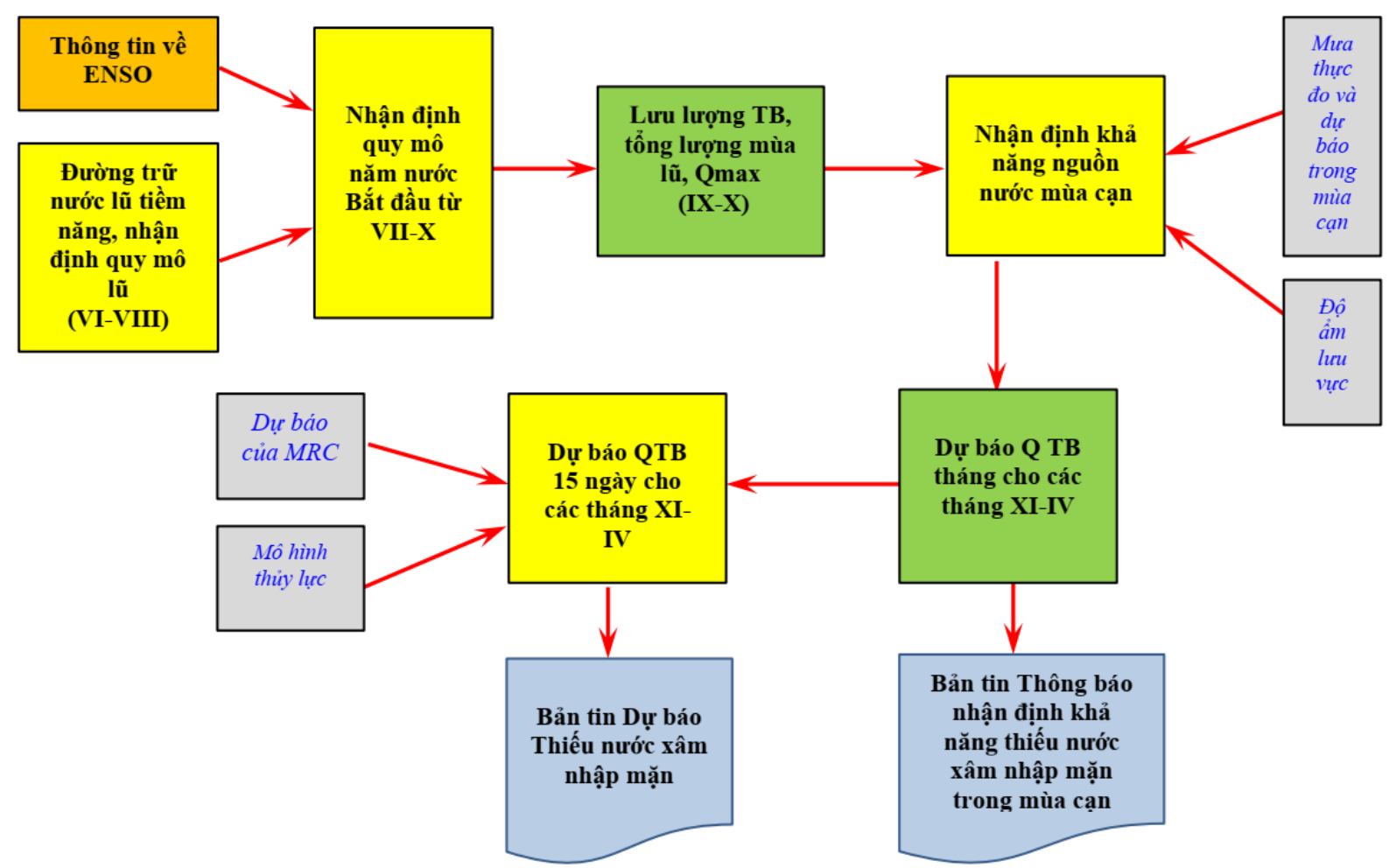

Hình 8. Lược đồ quy trình nhận định, thông báo sớm và dụ báo lương nước vào Việt Nam trong mùa can ở $B S C L$

\section{Tài liệu tham khảo}

1. Trung tâm Dự báo KTTV Quốc Gia, Các bản tin dụ báo trên web site http://www.nchmf.gov.vn/web/vi-VN/69/148/Default.aspx;

2. Viện QHTL Miền Nam. Các bản tin dụ báo trên web site http://siwrp.org.vn/news/duong-quatrinh-lu-dong-chinh-me-cong_581.html

3. Lê Đình Thành, Vai trò của biển hồ đối với chế độ dòng chảy hạ luu sông Mê Công, http://tapchivatuyentap.tlu.edu.vn/Portals/10/So 2014/06

4. Trịnh Quang Hòa, Huỳnh Minh Ngọc, Tổng quan về quan hệ và vai trò của biển hồ đối với dòng chảy sông Mê Công ở vùng Đồng bằng châu thổ, http://tapchivatuyentap.tlu.edu.vn/Portals/10/So209/14

5. Mekong River Commission - Hydro-Meteorological Database Hymos;

6. Mekong River Commission - Decision Support Framework (DSF);

7. Mekong River Commission - http://www.mrcmekong.org/mekong-flood-forecasting

8. BE Pengel, T Malone, and M Hartman, 2008. Towards a new flood forecasting system for the lower Mekong river basin. 


\title{
SCIENTIFIC BASIS TO RESEARCH WATER RESOURCES IN DRY SEASONS IN THE MEKONG BASIN
}

\author{
Tran Duc Thien ${ }^{1}$, Luu Thi Hong Linh ${ }^{1}$ \\ ${ }^{1}$ Water Resources Institute
}

\begin{abstract}
The research of water resources in the dry season in the Mekong Delta is very important in preventing drought, lack of water and saline intrusion. The hydrological characteristics of the Mekong and the Tonle Sap Riverare areas and the dry season flows are mainly contributed by the Mekong and Tonle Sap Rivers. Therefore, it is feasible to research the source of water into Vietnam in the dry season. Early identification of water resources in dry season is based on information on water resources during the flood season and the maximum reserve of Tonle Sap lake. On the other hand, identifying the scale of water resources is based on the potential flood storage curves of the basin. The relationship of flow between adjacent months is quite tight (correlation coefficient is greater than 0.8) is the basis for forecasting the next month's flow. A procedure of early identification of flows into Viet Nam during the dry season is also proposed in this article.
\end{abstract}

Keywords: Identifiying water resources in dry season, the MeKong basin. 